\title{
Modeling exchange rate exposure in the Japanese industrial sectors
}

\author{
P. Jayasinghe ${ }^{a}$, A.K. Tsui ${ }^{b}$ and Z.Y. Zhang \\ ${ }^{a}$ Department of Business Economics, University of Colombo, Sri Lanka \\ ${ }^{b}$ Department of Economics, National University of Singapore, Singapore \\ ${ }^{c}$ School of Accounting, Finance \& Economics, Edith Cowan University, Australia \\ Email: zhaoyong.zhang@ecu.edu.au
}

\begin{abstract}
In recent years the volatility of exchange rate exposure and its associated risk have become a hot issue in international financial management. It is often assumed that a firm's future operating cash flows is proxied by its market value, and the exposure coefficient would be able to efficiently measure the impact of exchange rate changes on a firm's return and its sensitivity to the changes. Recently, some studies begin to investigate whether exchange rate exposure is asymmetric between currency appreciations and depreciations. By far most existing studies on exchange rate exposure assume that the variances of a firm's returns and exchange rates changes are time-invariant. In this paper, we assess empirically the validity of this assumption, and argue that the conveniently defined exchange rate exposure is inadequate for measuring the entire impact of exchange rate changes on a firm's future operating cash flows in cases of time-varying variances. There are at least four alternative routes through which a firm's returns are exposed to foreign exchange risks when the variances are time-variant.
\end{abstract}

The four aspects of exchange rate exposure or the multi-elements of exchange rate exposure are defines as follows:

- the first route is that a firm's stock returns are exposed to the exchange rate changes either directly or indirectly through its business linkages with other firms.

- the second route captures the exposure to the volatility of exchange rate changes, namely, the sensitivity of a firm's value to the degree of fluctuations of exchange rates. If the degree of fluctuations is time-varying, the firm may react to change its marketing, production location and hedging strategies.

- the third level of exchange rate exposure measures the sensitivity of conditional variance of the returns to the volatility of exchange rate changes. Even if the second relationship is absent, as long as the conditional variances of returns are exposed to volatility of exchange rate changes and the returns are sensitive to its own volatility changes, there still exists the possibility of an indirect impact of exchange rate volatility on returns. As a consequence, the firm may have to re-assess and even change its current business strategies which may in turn affect its profitability.

- The fourth route indicates the time-varying conditional correlation between returns and exchange rate changes, through which the dynamics of a firm's exchange rate exposure will be captured.

We employ the bivariate GJR-GARCH-M models to investigate the four aspects of exchange rate exposure, by using data of the daily industrial indexes of ten sectors in Japan during the period from 1992 to 2000 . The results indicate that there are cases which are not exposed to currency risk under the conventional measure (exposure coefficient), but significantly exposed to currency risk through the alternative routes identified we find significant evidence of such exchange rate exposure which is not captured by the conventional measure. The diagnostic statistics confirm the adequacy of our model, and hence the robustness of the results.

Keywords: Exchange rate exposure; volatility spillovers; multivariate GARCH-M models; time-varying 


\section{INTRODUCTION}

In recent years the volatility of exchange rate exposure and its associated risk have become a hot issue in international financial management. Exchange rate exposure is empirically defined as the change in a firm's future operating cash-flows in response to changes in exchange rates. It is often assumed that a firm's future operating cash flows is proxied by its market value, and the exposure coefficient would be able to efficiently measure the impact of exchange rate changes on a firm's return and its sensitivity to the changes (Adler and Dumas, 1984). Recently, Kanas (1997) and Koutmos and Martin (2003) investigate whether exchange rate exposure is asymmetric between currency appreciations and depreciations. Kanas (2000), and Giurda and Tzavalia (2004) analyse asymmetry in volatility of stock returns related to exchange rate exposure at country level. Aloui (2007) explores the nature of the mean, volatility and causality transmission mechanism between stock and foreign exchange markets for the United States and some European markets. Raghavan and Dark (2008) use a Vector Autoregressive GARCH (VAR-GARCH) model to examine the return and volatility spillover effects between the US dollar/Australian dollar exchange rate and the Australian All Ordinaries Index (AOI).

By far most existing studies on exchange rate exposure assume that the variances of a firm's returns and exchange rates changes are time-invariant. In this paper, we assess empirically the validity of this assumption, and argue that the conveniently defined exchange rate exposure is inadequate for measuring the entire impact of exchange rate changes on a firm's future operating cash flows in cases of time-varying variances. There are at least four alternative routes through which a firm's returns are exposed to foreign exchange risks when the variances are time-variant, as illustrated in Figure 1.

In this paper, we employ a bivariate GARCH-type model to investigate the aforementioned sensitivities of exchange rate exposure by using daily industrial indexes of ten sectors in Japan during the period from 1992 to 2000. The results indicate that there are cases which are not exposed to currency risk under the conventional measure (exposure coefficient), but significantly exposed to currency risk through the alternative routes identified in Figure 1.

The rest of this paper is organized as follows. Section 2 discusses the theoretical framework and methodology used in this study. In section 3 we discuss briefly the datasets used in our study and analyze the empirical results. Some concluding remarks are given in Section 4.

\section{METHODOLOGY AND THE MODEL}

The first movement of exchange rate exposure has been thoroughly discussed in the literature during the last two decades (among others, see Adler and Dumas, 1984; Jorion, 1990). The augmented market model is often used to estimate the exchange rate exposure coefficients in the mean equation as follows:

$$
\begin{aligned}
& r_{i, t}=a_{0}+a_{m} r_{m, t}+a_{x} r_{x, t}+\xi_{i, t} \quad i=1,2, \ldots n, \\
& \text { and } \xi_{i, t} \sim N\left(0, \sigma^{2}\right)
\end{aligned}
$$

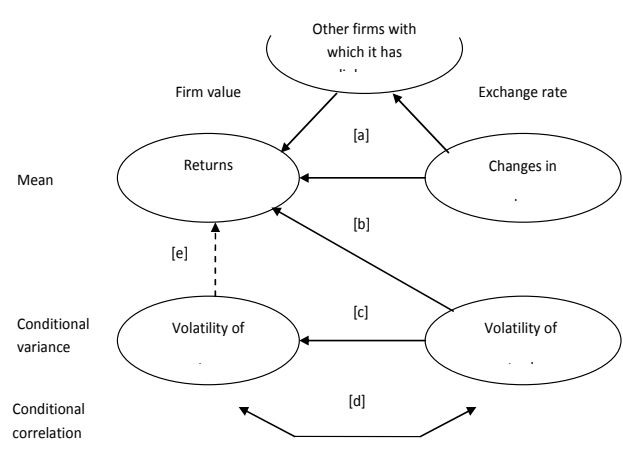

Figure 1. Multi-elements of exchange rate

where $r_{i, t}$ is returns on firm $i$ 's stock at time $t ; r_{m, t}$ is returns on market portfolio at time $t ; r_{x, t}$ is changes in exchange rate at time $t$. Here the exchange rate is expressed as the local currency price of one unit of the foreign currency; $a_{m}$ is firm $i$ 's exposure to market returns; $a_{x}$ is firm $i$ 's exchange rate exposure coefficient which measures the sensitivity of a firm's returns to the exchange rate movements; and $\xi_{i, t}$ is the regression residual which is assumed to follow a normal distribution with zero mean and constant variance.

The major problem of the augmented market approach is the questionable assumption of time-invariance in the variance of firm's return and in changes of exchange rate. In recent years, it has become common to use generalized autoregressive conditional heteroskedasticity (GARCH)-type models to accommodate the timevarying volatility in empirical studies of exchange rate changes. The conditional volatility literature has been 
discussed extensively in recent years (see, for example, Li, Ling and McAleer, 2002; McAleer, 2005; and McAleer, Chan and Marinova, 2007).

In this study we employ a time-varying conditional correlation bivariate GJR-GARCH(1,1)-M model (Glosten et al., 1993) to capture the four elements of exchange rate exposure of sectoral returns. According to Engle et al. (1987), as the degree of risk associated with the returns on assets is likely to vary over time, the compensation required by risk averse investors for holding such assets must also be time-varying, which was hence incorporated into their asset pricing models with a GARCH-in-mean term. This provides some justification for our choice of the GJR-GARCH models. The typical specification underlying the bivariate conditional mean and conditional variance in returns are given as follow:

$$
\begin{aligned}
& r_{i, t}=a_{0}+a_{m} r_{m, t}+a_{x-1} r_{x, t-1}+\sum_{k=1}^{q} a_{j-k} r_{i, t-k}+a_{g}\left(h_{x, t-1}\right)^{1 / 2}+\varepsilon_{i, t} ; \quad i=1,2, \ldots n \\
& r_{x, t}=b_{0}+\sum_{l=1}^{s} b_{x-l} r_{x, t-l}+\varepsilon_{x, t} \\
& z_{t}=\varepsilon_{t} H_{t}^{-1 / 2} \\
& \varepsilon_{t}\left|I_{t-1}=\left(\varepsilon_{i, t} \varepsilon_{x, t}\right)^{\prime}\right| I_{t-1} \sim f_{v}\left(\varepsilon_{t} \mid I_{t-1}\right) \\
& h_{i, t}=\omega_{i}+\alpha_{i} \varepsilon_{i, t-1}^{2}+\gamma_{i} d_{i, t-1} \varepsilon_{i, t-1}^{2}+\beta_{i} h_{i, t-1}+\alpha_{i x} \varepsilon_{x, t-1}^{2}+\gamma_{i x} d_{x, t-1} \varepsilon_{x, t-1}^{2} \\
& h_{x, t}=\omega_{x}+\alpha_{x} \varepsilon_{x, t-1}^{2}+\gamma_{x} d_{x, t-1} \varepsilon_{x, t-1}^{2}+\beta_{x} h_{x, t-1} \\
& h_{i x, t}=\rho_{i x, t}\left(h_{i, t} h_{x, t}\right)^{1 / 2}
\end{aligned}
$$

where $r_{i, t}$ is returns on sectoral index $i$ at time $t ; r_{m, t}$ is returns on market index at time $t ; r_{x, t}$ is the log difference in exchange rate at time $t$. In addition, $\mathcal{E}_{t}$ is a $2 \times 1$ vector of the daily shocks of $\left(\mathcal{E}_{i, t} \mathcal{E}_{x, t}\right)$ at time $t$ pair-wise with each sector $i$. And $\varepsilon_{t} \mid I_{t-1}$ denote the $2 \times 1$ vector of random shocks at time $t$ given all available information at time $(t-1)$. We assume that it follows a bivariate $t$-distribution with $v$ degrees of freedom, zero mean and conditional variance $H_{t}$, which is a $2 \times 2$ variance-covariance matrix. For each sector, the main diagonal elements of $H_{t}$ are the conditional variances of sectoral returns and changes in exchange rate, represented by $h_{i, t}$ and $h_{x, t}$, respectively. The two conditional variances are assumed to follow GJR-GARCH(1,1) structure given by equations (4) and (5), and $d_{u, t-1}=1$ if $\varepsilon_{u, t-1}<0$ and zero otherwise for $u=i, x$. Finally, $z_{t}$ denotes the standardized errors which are assumed to be independently and identically distributed with mean 0 and variance 1 .

The conditional covariance of sectoral returns and exchange rate changes is defined by equation (7), specified as the product of conditional correlation coefficient and the square root of the conditional variance of returns and exchange rate changes. Following Tse and Tsui (2002), we assume that the conditional correlation between sectoral returns and exchange rate changes is time-varying, and can be specified as:

$$
\rho_{i x, t}=\left(1-\theta_{1}-\theta_{2}\right) \bar{\rho}_{i x}+\theta_{1} \rho_{i x, t-1}+\theta_{2} \psi_{t-1}
$$

As such, the conditional correlation at time $t\left(\rho_{i x, t}\right)$ is given by the weighted average of time-invariant component $\left(\bar{\rho}_{i x}\right)$, its own lag term in previous period $\left(\rho_{i x, t-1}\right)$ and $\psi_{i x, t-1}$ which is assumed to be a function 
Jayasinghe et al., Modeling Exchange Rate Exposure in the Japanese Industrial Sectors

of lagged observations of standardized error $z_{t}$. More specifically, $\psi_{i j, t}=\frac{\sum_{h=1}^{M} z_{i, t-h} z_{j, t-h}}{\sqrt{\left(\sum_{h=1}^{M} z_{i, t-h}^{2}\right)\left(\sum_{h=1}^{M} z_{j, t-h}^{2}\right)}}$. Both $\theta_{1}$ and $\theta_{2}$ are non-negative and $\left(\theta_{1}+\theta_{2}\right) \leq 1$

Assuming that the standardized residuals of the suggested bivariate model are $t$-distributed, the conditional $\log$-likelihood of residual vector $\mathcal{E}_{t}$ at time $t$ can be defined as follows:

$\ell(\varphi)_{t}=\ln \Gamma\left(\frac{v+2}{2}\right)-\ln \Gamma\left(\frac{v}{2}\right)-\ln (\pi(v-2))-\frac{1}{2} \ln \left|H_{t}\right|-\left(\frac{v+2}{2}\right) \ln \left(1+\frac{\varepsilon_{t}^{\prime}\left(D_{t} R_{t} D_{t}\right)^{-1} \varepsilon_{t}}{v-2}\right)$

where $\varphi$ is the vector of parameters to be estimated; $\Gamma($.$) is the Gamma function; D_{t}$ is a $2 \times 2$ diagonal matrix whose diagonal elements are $h_{i, t}^{1 / 2}$ and $h_{x, t}^{1 / 2} ; R_{t}$ is the $2 \times 2$ conditional correlation matrix whose diagonal elements consist of ones and off-diagonal elements are represented by $\rho_{i x, t}$.

The log-likelihood function of the sample is obtained as: $L(\phi)=\sum_{t=1}^{T} \ell(\varphi)_{t}$, where $T$ is the number of observations. The parameter vector $\varphi$ of the bivariate GJR-GARCH-M model is estimated by maximizing $L$ with respect to $\varphi$. All estimates of the parameters in this paper are obtained by the method of maximum likelihood using programs coded in GAUSS.

\section{EMPIRICAL ANALYSIS}

\subsection{Data Description}

Our dataset consists of ten industrial sectors of the Japanese economy during the period from June 1, 1992 to December 12, 2000, and contains 2240 observations. The choice of this sample is based on availability of data. In selecting the sectoral returns, we focus on level 04 industrial classification, which is based on FTSE actuaries system, available in Datastream. We choose 10 out of the 39 sectors which are reasonably related to manufacturing goods, including automobile and parts (A\&P), construction and building materials $(\mathrm{C} \& \mathrm{BM})$, diversified industries (DI), electrical and electronic equipment (E\&EE), engineering and machinery (E\&M), information technology and hardware (IT\&H), oil and gas (O\&G), pharmaceuticals and biotechnology $(\mathrm{P} \& \mathrm{~B})$, software and computer services (S\&CS) and steel and other metals (S\&OM), respectively. Market portfolio is assumed to be represented by Nikkei 225, the overall stock index in Japan. And all sectoral returns and market returns are expressed in local currency.

The continuously compounded daily returns and exchange rate changes are computed as follows:

$r_{u, t}=\ln \left(R_{u, t} / R_{u, t-1}\right) * 100 \quad u=i, x, m$

where $R_{u, t}$ and $R_{u, t-1}$ are the closing values of stock prices/exchange rates for the trading days $t$ and $t$ - 1 , respectively.

Table 1 displays the summary statistics of returns from the industrial sectors and the market portfolio represented by Nikkei 225. The highest two daily returns are found in IT\&H and S\&CS, averaging $0.036 \%$ and $0.061 \%$, respectively. The lowest two daily returns are in E\&M and S\&OM, with negative averages at $0.13 \%$ and $0.04 \%$, respectively. The mean daily return of the market portfolio is at a loss of $0.013 \%$, with a maximum gain at $7.66 \%$ and a loss at $7.23 \%$, respectively. The standard deviations for returns from these industrial sectors range from $1.086 \%(\mathrm{P} \& \mathrm{~B})$ to $2.063 \%$ (S\&CS). Out of these 14 sectors, PC\&H and P\&B are the least volatile, while DI and S\&CS are the most volatile. Moreover, returns of the market portfolio and those of 13 out of the 14 industrial sectors are positively skewed and highly leptokurtic with all values of kurtosis greater than 3 , thereby exceeding the kurtosis of returns following a normal distribution. As all the series are I(1) processes, we have conducted the Johansen cointegration test. The results are not support of 
co-integration between sectoral index and the exchange rate during the sample period, thereby suggesting that the error correction terms are not required in the mean equations.

Table 1: Preliminary statistics of sectoral returns

\begin{tabular}{lllllllllllll}
\hline Sector & A\&P & C\&BM & DI & E\&EE & E\&M & IT\&H & O\&G & P\&B & S\&CS & S\&OM & Nikkei \\
\hline Mean & 0.0232 & -0.0333 & 0.0176 & 0.0197 & -0.1301 & 0.0359 & -0.0323 & 0.0289 & 0.0614 & -0.0367 & -0.0128 \\
Maximum & 9.3574 & 9.5442 & 12.2568 & 7.0290 & 6.6456 & 9.4960 & 11.0045 & 9.2439 & 14.5879 & 10.4532 & 7.6605 \\
Minimum & -9.3680 & -7.4895 & -7.1448 & -6.3572 & -7.4734 & -7.7137 & -10.4589 & -4.4810 & -10.8411 & -7.2041 & -7.2340 \\
S D & 1.3832 & 1.2744 & 1.7504 & 1.2285 & 1.2441 & 1.5712 & 1.6440 & 1.0863 & 2.0631 & 1.5686 & 1.3953 \\
Skewness & 0.0643 & 0.6663 & 0.4379 & 0.0150 & 0.0424 & 0.0887 & 0.1817 & 0.3903 & 0.0412 & 0.5998 & 0.1421 \\
Kurtosis & 6.9657 & 8.6346 & 6.5645 & 5.9163 & 6.2023 & 5.9194 & 6.8827 & 7.1528 & 7.5041 & 7.2939 & 5.8218 \\
Jarque-Bera & 1469.39 & 3128.97 & 1257.48 & 793.86 & 957.79 & 798.41 & 1419.36 & 1666.44 & 1894.11 & 1855.10 & 750.69 \\
Q (20) & 46.76 & 50.40 & 31.68 & 69.37 & 36.96 & 111.92 & 28.44 & 23.94 & 277.01 & 62.82 & 22.48 \\
Q (20) & 774.19 & 49579 & 293.29 & 358.87 & 412.70 & 623.27 & 595.27 & 349.45 & 2010.50 & 463.97 & 402.39 \\
Runs Test & 0.15 & 4.02 & 2.14 & -3.24 & -3.13 & -5.53 & 2.12 & 2.12 & -7.44 & -3.29 & 2.76 \\
ADF (price) & -3.38 & -2.22 & -2.61 & -2.71 & -2.04 & -1.75 & -2.34 & -1.89 & -2.33 & -2.42 & -2.68 \\
ADF (returns) & -47.87 & -41.90 & -49.61 & -41.14 & -42.72 & -39.27 & -49.19 & -47.26 & -34.91 & -41.84 & -49.41
\end{tabular}

Notes: $Q(20)$ and $Q^{2}(20)$ are Ljung-Box statistics of returns and squared returns for 20 lags. They follow a $\chi^{2}$ distribution and the critical value at the $5 \%$ level of significance with 20 degrees of freedom is 31.41 . ADF (price) and ADF (return) represent the critical value at the $5 \%$ level of significance with 20 degrees of freedom is 31.41 . ADF (p
augmented Dicky Fuller statistic with an intercept for stock prices and returns, respectively.

\subsection{Empirical Results}

Table 2 reports the maximum likelihood estimates of the time-varying conditional correlation GJRGARCH(1,1)-M model. The results indicate that over half of the 10 Japanese industries are significantly exposed to exchange rate changes in terms of their returns, implying the existence of the first moment of exchange rate exposure. The absolute value of estimated exposure coefficient represented by $a_{x-1}$ ranges from 0.0523 in $C \& B M$ to 0.1522 in $\mathrm{O} \& \mathrm{G}$, and there are four cases with the exposure coefficients being greater than 0.1 , which suggests that returns in those sectors are relatively highly sensitive to the changes in exchange rate.

It is interesting to note that returns in some sectors such as A\&P, E\&EE and IT\&H are positively related to the exchange rate changes, implying that returns on such sectors increase with the depreciation of the yen. This finding is consistent with our causal observation that devaluation of the currency would favour the exporting sectors. The negative relationship between $O \& G$ and exchange rate changes can be attributed to Japan's heavy import reliance in that sector. Although lack of all the natural resources, Japan is the world's third largest oil consumer and second largest energy importer (EIA, 2004). Our findings are also consistent with that by Bodnar and Gentry (1993) and Dominguez (1998), who report that electrical machinery, precision instruments and industrial sectors are positively exposed to exchange rate changes while the energy and utilities sectors show the opposite result. Returns in the C\&BM sector are also found negatively exposed. However, unlike the O\&G sector, it is difficult to craft a clear-cut explanation for this in terms of imports and exports. The difficulty is partly due to the different classification systems used in sectoral stock indexes and import/export data. On the other hand, it is not sensible to solely attribute exchange rate exposure of sectoral returns to the aggregated import/export trade statistics.

Regarding the estimates of the GARCH-M term, we find evidence of volatility of exchange rate exposure in three out of the ten sectors. It is also interesting to note that, though S\&CS and S\&OM sectors are exposed to the volatility of exchange rate, they are not exposed to the exchange rate changes. The estimated coefficient of own GJR term $\left(\gamma_{i}\right)$ are significant at the 5\% level and bear the expected positive sign in seven industrial sectors including A\&P, C\&BM, DI, E\&M, O\&G, P\&B and S\&OM, suggesting that the leverage effect is at work when there is a reduction in sectoral returns. The results confirm the existence of asymmetric volatility in returns in these seven sectors. Volatility associated with exchange rate changes is also found to be asymmetric in five sectors (the results are not reported but available upon request from the authors). 
Jayasinghe et al., Modeling Exchange Rate Exposure in the Japanese Industrial Sectors

\begin{tabular}{|c|c|c|c|c|c|c|c|c|c|c|}
\hline Parameter & A\&P & C\&BM & DI & E\&EE & E\&M & IT\&H & O\&G & $P \& B$ & S\&CS & ${\mathrm{S} \& O M^{\S}}^{\S}$ \\
\hline 1. $a_{x-1}$ & $\begin{array}{l}0.1405^{* * *} \\
(6.30)\end{array}$ & $\begin{array}{l}-0.0523^{* * *} \\
(-3.18)\end{array}$ & $\begin{array}{l}0.0161 \\
(0.45)\end{array}$ & $\begin{array}{l}0.1175^{* * *} \\
(6.57)\end{array}$ & $\begin{array}{l}0.0277^{*} \\
(1.84)\end{array}$ & $\begin{array}{l}0.1500^{* * *} \\
(5.80)\end{array}$ & $\begin{array}{l}-0.1522^{* * *} \\
(-6.19)\end{array}$ & $\begin{array}{l}-0.0239 \\
(-1.26)\end{array}$ & $\begin{array}{l}-0.0295 \\
(-0.78)\end{array}$ & $\begin{array}{l}0.0103 \\
(0.39)\end{array}$ \\
\hline 2. $a_{g}$ & $\begin{array}{l}-0.0356 \\
(-0.51)\end{array}$ & $\begin{array}{l}0.0618 \\
(1.26)\end{array}$ & $\begin{array}{l}0.0957 \\
(0.95)\end{array}$ & $\begin{array}{l}0.0295 \\
(0.54)\end{array}$ & $\begin{array}{l}-0.0130 \\
(-0.28)\end{array}$ & $\begin{array}{l}0.1646^{* *} \\
(2.13)\end{array}$ & $\begin{array}{l}-0.0759 \\
(-1.11)\end{array}$ & $\begin{array}{l}0.0266 \\
(0.49)\end{array}$ & $\begin{array}{l}0.2604^{* *} \\
(2.35)\end{array}$ & $\begin{array}{l}-0.1635^{* *} \\
(-2.10)\end{array}$ \\
\hline 3. $\alpha_{i}$ & $\begin{array}{l}0.0800^{* * *} \\
(4.13)\end{array}$ & $\begin{array}{l}0.0894 * * * \\
(3.91)\end{array}$ & $\begin{array}{l}0.0449^{* * *} \\
(3.62)\end{array}$ & $\begin{array}{l}0.0762 * * * \\
(4.08)\end{array}$ & $\begin{array}{l}0.0549 * * * \\
(3.25)\end{array}$ & $\begin{array}{l}0.0827 * * * \\
(3.90)\end{array}$ & $\begin{array}{l}0.0555^{* * *} \\
(3.09)\end{array}$ & $\begin{array}{l}0.0602^{* * *} \\
(2.90)\end{array}$ & $\begin{array}{l}0.1668^{* * *} \\
(6.17)\end{array}$ & $\begin{array}{l}0.0775^{* * *} \\
(4.27)\end{array}$ \\
\hline 4. $\gamma_{i}$ & $\begin{array}{l}0.0568^{* *} \\
(2.07)\end{array}$ & $\begin{array}{l}0.0736^{* * *} \\
(2.85)\end{array}$ & $\begin{array}{l}0.0335^{* *} \\
(1.99)\end{array}$ & $\begin{array}{l}0.0196 \\
(0.91)\end{array}$ & $\begin{array}{l}0.0690 \text { *** } \\
(3.12)\end{array}$ & $\begin{array}{l}0.0279 \\
(1.31)\end{array}$ & $\begin{array}{l}0.0458^{* *} \\
(2.31)\end{array}$ & $\begin{array}{l}0.0387^{* *} \\
(1.97)\end{array}$ & $\begin{array}{l}0.0496 \\
(1.40)\end{array}$ & $\begin{array}{l}0.0555^{* *} \\
(2.24)\end{array}$ \\
\hline 5. $\alpha_{i x}$ & $\begin{array}{l}0.0352^{*} \\
(1.64)\end{array}$ & $\begin{array}{l}0.0171^{*} \\
(1.78)\end{array}$ & $\begin{array}{l}0.1597 * * * \\
(3.37)\end{array}$ & $\begin{array}{l}0.0142 \\
(1.61)\end{array}$ & $\begin{array}{l}0.0175^{* *} \\
(2.30)\end{array}$ & $\begin{array}{l}0.0197 \\
(0.92)\end{array}$ & $\begin{array}{l}0.0112 \\
(0.92)\end{array}$ & $\begin{array}{l}0.0109 \\
(1.12)\end{array}$ & $\begin{array}{l}0.1112^{*} \\
(1.83)\end{array}$ & $\begin{array}{l}0.0678^{* *} \\
(2.25)\end{array}$ \\
\hline 6. $\gamma_{i x}$ & $\begin{array}{l}-0.0213 \\
(-0.87)\end{array}$ & $\begin{array}{l}-0.0189 * \\
(-1.67)\end{array}$ & $\begin{array}{l}-0.1924^{* * *} \\
(3.51))\end{array}$ & $\begin{array}{l}-0.0142 \\
(-1.37)\end{array}$ & $\begin{array}{l}-0.0175^{* *} \\
(-2.05)\end{array}$ & $\begin{array}{l}-0.0124 \\
(-0.46)\end{array}$ & $\begin{array}{l}0.0013 \\
(0.08)\end{array}$ & $\begin{array}{l}-0.0068 \\
(-0.54)\end{array}$ & $\begin{array}{l}-0.0867 \\
(1.17)\end{array}$ & $\begin{array}{l}-0.0513 \\
(-1.46)\end{array}$ \\
\hline 7. $\beta_{i}$ & $\begin{array}{l}0.8808^{* * *} \\
(36.32)\end{array}$ & $\begin{array}{l}0.8729 * * * \\
(35.60)\end{array}$ & $\begin{array}{l}0.9274 * * * \\
(67.64)\end{array}$ & $\begin{array}{l}0.9019^{* * *} \\
(42.28)\end{array}$ & $\begin{array}{l}0.9002^{* * *} \\
(46.04)\end{array}$ & $\begin{array}{l}0.8963^{* * *} \\
(39.89)\end{array}$ & $\begin{array}{l}0.9244^{* * *} \\
(60.33)\end{array}$ & $\begin{array}{l}0.9143^{* * *} \\
(39.70)\end{array}$ & $\begin{array}{l}0.8000^{* * *} \\
(29.08)\end{array}$ & $\begin{array}{l}0.8705^{* * *} \\
(42.47)\end{array}$ \\
\hline 8. $\bar{\rho}_{i x}$ & $\begin{array}{l}0.0539^{*} \\
(1.75)\end{array}$ & $\begin{array}{l}-0.0496 \\
(-1.58)\end{array}$ & $\begin{array}{l}-0.0050 \\
(-0.16)\end{array}$ & $\begin{array}{l}0.0848^{* * *} \\
(3.13)\end{array}$ & $\begin{array}{l}0.0246 \\
(1.03)\end{array}$ & $\begin{array}{l}0.0635^{* *} \\
(2.44)\end{array}$ & $\begin{array}{l}-0.0582^{* *} \\
(-2.09)\end{array}$ & $\begin{array}{l}-0.0258 \\
(-0.91)\end{array}$ & $\begin{array}{l}-0.0086 \\
(-0.27)\end{array}$ & $\begin{array}{l}-0.0496^{* *} \\
(-2.13)\end{array}$ \\
\hline 9. $\theta_{1}$ & $\begin{array}{l}0.9927 * * * \\
(63.76)\end{array}$ & $\begin{array}{l}0.9784^{* * *} \\
(35.21)\end{array}$ & $\begin{array}{l}0.9747 * * * \\
(24.96)\end{array}$ & $\begin{array}{l}0.9775^{* * *} \\
(24.44)\end{array}$ & $\begin{array}{l}0.7156 \\
(1.40)\end{array}$ & $\begin{array}{l}0.8780^{* * *} \\
(5.61)\end{array}$ & $\begin{array}{l}0.9671^{* * *} \\
(20.35)\end{array}$ & $\begin{array}{l}0.9770^{* * *} \\
(47.85)\end{array}$ & $\begin{array}{l}0.9979 * * * \\
(139.51)\end{array}$ & $\mathrm{NA}$ \\
\hline 10. $\theta_{2}$ & $\begin{array}{l}0.0012 \\
(0.41)\end{array}$ & $\begin{array}{l}0.0056 \\
(0.95)\end{array}$ & $\begin{array}{l}0.0064 \\
(0.88)\end{array}$ & $\begin{array}{l}0.0026 \\
(0.44)\end{array}$ & $\begin{array}{l}0.0083 \\
(0.04)\end{array}$ & $\begin{array}{l}0.0114 \\
(0.80)\end{array}$ & $\begin{array}{l}0.0049 \\
(0.67)\end{array}$ & $\begin{array}{l}0.0041 \\
(0.82)\end{array}$ & $\begin{array}{l}0.0003 \\
(0.10)\end{array}$ & NA \\
\hline 11. $v$ & $\begin{array}{l}4.9612 * * * \\
(12.87)\end{array}$ & $\begin{array}{l}5.4010^{* * *} \\
(12.17)\end{array}$ & $\begin{array}{l}5.2667 * * * \\
(12.27)\end{array}$ & $\begin{array}{l}5.8365^{* * *} \\
(11.80)\end{array}$ & $\begin{array}{l}6.2954 * * * \\
(10.87)\end{array}$ & $\begin{array}{l}5.4368^{* * *} \\
(11.83)\end{array}$ & $\begin{array}{l}5.4290 * * * \\
(12.08)\end{array}$ & $\begin{array}{l}5.2129 * * * \\
(12.18)\end{array}$ & $\begin{array}{l}5.8265^{* * *} \\
(11.33)\end{array}$ & $\begin{array}{l}5.3226^{* * * *} \\
(12.58)\end{array}$ \\
\hline
\end{tabular}

Notes: $* * *, * *$ and $*$ indicate $1 \%, 5 \%$ and $10 \%$ levels of significance, respectively; Values mentioned within parentheses are relevant $t$-statistics; The estimated model consists of the Equations $3 \mathrm{~b}$ through $9 .{ }^{8}$ For S\&OM, constant correlation model is used as the time-varying version of the suggested model did not converge. Except for the time-varying correlation parameters, the results from the two versions of the model are largely similar and available upon request; NA: Not available.

It is found that the cross squared error $\left(\alpha_{i x}\right)$ is positive and significant at the $5 \%$ significant level in sectors DI, E\&M and S\&OM, and significant at the 10\% significant level in A\&P, C\&BM and S\&CS. The results confirm the "meteoric shower" effect in these industrial sectors, and suggest that an increase in the volatility in exchange rates will raise the volatility of sectoral returns. Moreover, the coefficient of the cross GJR term $\left(\gamma_{i x}\right)$ is found to be negative and significant in the sectors of DI, E\&M and C\&BM (row 6 in Table 3), suggesting the asymmetric exchange rate exposure of the conditional variance in these sectors. The implication is that the returns in these three sectors are not only highly sensitive to the volatility in foreign exchange market, but also vulnerable to the depreciation of yen. It is also found that the time-varying conditional correlation model converges in nine industrial sectors, of which the time-invariant component of the correlation $\left(\bar{\rho}_{i x}\right)$ is significant only in three cases. Moreover, $\theta_{1}$ is found highly significant in eight sectors. These results suggest there exist two different patterns of time-varying conditional correlation between Japanese industrial sectors and the exchange rate changes. The first one is that, although the correlation between the returns and exchange rate changes are time-varying in these sectors, time varying correlation is more likely to be dependent on its own past and less likely to be disturbed by the recent changes as reflected in the standardized residuals. The second one is that although the time-invariant component is not significant, time-variant component is significant, suggesting that the time-invariant component alone is not a reliable measure of the correlation between the two variables.

We have also estimated the multi-elements of exchange rate exposure associated with a yen-US dollar bilateral exchange rate. The results (not reported but available upon request) are similar to the one with tradeweighted. The diagnostic test and also the Box-Pierce test confirm that the non-linear dependencies in almost all the sectoral indexes have been adequately captured by the proposed model, and the proposed bivariate GJR-GARCH(1,1)-M model is adequate for capturing all the four elements of exchange rate exposure of sectoral returns.

\section{CONCLUDING REMARKS}

We employ a bivariate time-varying conditional correlation GJR-GARCH(1,1)-M model to estimate the multi-elements of exchange rate exposure in the ten Japanese industrial sectors. We find strong evidence for the existence of all the four elements of exchange rate exposure in the sectoral returns. The results confirm the first moment exposure to exchange rate changes in the six sectors, A\&P, C\&BM, E\&EE, E\&M, IT\&H and $\mathrm{O} \& \mathrm{G}$, and that the returns in three sectors (IT\&H, S\&CS and S\&OM) are significantly exposed to the 
volatility of exchange rate changes. The conditional variances of the returns in three sectors (DI, E\&M and $\mathrm{S} \& \mathrm{OM}$ ) are found to be significantly exposed to the volatility of exchange rate changes. The exchange rate exposure of the conditional variances of the returns in three sectors (DI, E\&M and C\&BM) are found asymmetric, implying that the volatility increase in sectoral returns caused by a depreciation of yen would be greater than that caused by an appreciation of the same magnitude. We find strong evidence that returns in nine sectors are significantly correlated with the exchange rate changes and the correlation is time-varying. In addition, the time-varying correlation between sectoral returns and exchange rate changes is more persistent.

This study provide strong evidence suggesting that the commonly employed exposure coefficient/beta is inadequate to capture the entire impact of exchange rate changes on firms' future operating cash flows. In the presence of those "other" elements of exchange rate exposure, the entire currency risk actually faced by a firm/sector is not fully captured by the "exchange rate exposure coefficient" alone. As such, taking the conventional exposure coefficient as the sole measure of exchange rate exposure of firms/sectors may provide us with misleading results. There are cases which are not exposed to currency risk under the conventional measure, but are found significantly exposed to the currency risk through the four alternative routes identified in this paper. The diagnostic statistics further confirm the adequacy of our model, and hence the robustness of the results.

\section{REFERENCES}

Adler, M. and B. Dumas (1984) "Exposure to Currency Risk: Definition and Measurement", Financial Management, 13, pp. 41-50.

Aloui, C. (2007), "Price and volatility spillovers between exchange rates and stock indexes for the pre- and post-euro period", Quantitative Finance 7(6), pp 669-685.

Bodnar, G. M. and W. M. Gentry (1993) "Exchange Rate Exposure and Industry Characteristics: Evidence from Canada, Japan and the USA", Journal of International Money and Finance, 12, pp. 29-45.

Dominguez, K. M. E. (1998) "The Dollar Exposure of Japanese Companies", Journal of the Japanese and International Economies, 12, pp. 388-405.

EIA (2004) "Country Analysis Briefs: Japan", Energy Information Administration http://www.eia.doe.gov/emeu/cabs/japan.html.

Engle, R. F., D. M. Lilien and R. P. Robins (1987) "Estimating Time-Varying Risk Premia in the Time Structure: The ARCH-M Model", Econometrica, 55(2), pp. 391-407.

Giurda, F. and E. Tzavalia (2004), "Is the Currency Risk Priced in Equity Markets?”, Working Paper \# 511, Department of Economics, Queen Mary University of London

Glosten, L., R. Jegannathan and D. Runkle (1993) "On the Relation between the Expected Value and Volatility of Nominal Excess Return on Stock”, Journal of Finance, 46, pp. 1779-1801.

Jorion, P. (1990) "The Exchange Rate Exposure of U.S. Multinationals", Journal of Business, 63, pp. 331345.

Kanas, A. (1997) "Is Economic Exposure Asymmetric between Long-Run Depreciations and Appreciations? Testing Using Cointegration Analysis", Journal of Multinational Financial Management, 7, pp. 27-42

Kanas, A. (2000), "Volatility Spillovers between Stock Returns and Exchange Rate Changes", Journal of Business and Finance and Accounting, 27 (3), April/May, pp. 447-67.

Koutmos, G. and A. D. Martin (2003) "First and Second Moment Exchange Rate Exposure: Evidence from U.S. Stock Returns", The Financial Review, 38, pp. 455-71.

Li, W.K., S. Ling and M. McAleer (2002), Recent theoretical results for time series models with GARCH errors, Journal of Economic Surveys, 16, 245-269.

McAleer, M. (2005), Automated inference and learning in modeling financial volatility, Econometric Theory, 21, 232-261.

McAleer, M., F. Chan and D. Marinova (2007), An econometric analysis of asymmetric volatility: theory and application to patents, Journal of Econometrics, 139, 259-284.

Raghavan, M. and J. Dark (2008) "Return and Volatility Spillovers Between the Foreign Exchange Market and the Australian All Ordinaries Index", The ICFAI Journal of Applied Finance 14, pp. 41-48.

Tse, Y. K. and A. K. Tsui (2002) "A Multivariate GARCH Model with Time-Varying Correlations", Journal of Business and Economic Statistics, 20, pp. 351-62. 